Arhe XVIII, 35/2021

UDK 13 Kant I.

111.62 Kant I.

DOI https://doi.org/10.19090/arhe.2021.35.99-121

Originalni naučni rad

Original Scientific Article

\author{
STANKO VLAŠKI ${ }^{1}$ \\ Univerzitet u Novom Sadu, Filozofski fakultet
}

\title{
KANTOV POJAM PROMENE
}

Sažetak: U radu se nastoji pokazati da smisao revolucionarnog prevrata koji se u filozofiji dešava $\mathrm{s}$ Kantovom kritičkom filozofijom može biti preispitivan i razmatranjem samog Kantovog poimanja promene. Kantova primedba da sâm razum uopšte ne može shvatiti kako je promena moguća, dovodi se u vezu s pojedinim među temeljnim uvidima zapadne metafizike, a konkretno s elejskim poricanjem mogućnosti da se promena misli, odnosno s negiranjem njene zbiljnosti kao takve. Autor želi da pokaže da Kantovi napori da integriše pojam promene u sistem transcendentalnog saznanja struktura subjektivnosti treba da budu tumačeni u svetlu njegovog rada na obelodanjenju uslova mogućnosti sintetičkog apriornog znanja. Promena se pokazuje upravo $z a$ živo sadejstvo razuma i čulnosti, pojma i opažaja, $i$ kao to sadejstvo sâmo. Kantov stav da je promena moguća zahvaljujući apriornosti vremena, kojim se ujedno prihvata determinisanost svega budućeg onim prošlim, a shodno tome i nužno važenje zakona kauzaliteta, u završnom delu rada tumači se kao ključ za razumevanje razloga zbog kojih Kant odbacuje mogućnost da se promeni priznaju apsolutna prava. Za Kanta, deterministički shvaćenoj promeni ne priznaje se apsolutni dignitet, i to za dobro onoga u čemu jeste istinsko ljudsko dostojanstvo - moralne slobode. Utoliko, sfera moralne slobode kod Kanta je morala ostati s onu stranu rasprava o biću promene.

Ključne reči: Kant, promena, analitičko znanje, sintetički apriorni sudovi, vreme, kauzalitet, Parmenid, Zenon iz Eleje, početak, sloboda

\section{POJMITI PROMENU?}

Zahteva li se od filozofije da reflektuje sopstveni povesni hod, jedan od stožera njene samoidentifikacije već dva stoleća jeste uvid da se $\mathrm{s}$

\footnotetext{
${ }^{1}$ E-mail adresa autora: stanko.vlaski@ff.uns.ac.rs
} 
Kantovim [Immanuel Kant] projektom kritike uma dešava radikalna, revolucionarna promena $\mathrm{u}$ filozofskom mišljenju. Temelji takve samoidentifikacije položeni su načinom na koji je sâm Kant osvešćivao domašaje prevrata koji za filozofiju znači njegova Kritika čistoga uma. Da je u njoj reč jedino o premeštanju težišta filozofskih interesovanja s objekta na subjekt saznanja, kako se to ponekad pojednostavljeno prihvata, ona ne bi imala osnova da traži da joj se priznaju prava začetnice promene u filozofiji koja bi se, kako je to zabeleženo na stranicama predgovora drugom izdanju Kritike čistoga uma, poredila s onom koju je nauci astronomije doneo Nikola Kopernik. Već u Kantovo vreme, takvo premeštanje slovilo je trajnim misaonim dobrom kartezijanstva. Za Kanta, nije stalo samo do toga da se pokaže prvenstvo subjekta spram objekta saznanja u spoznajnom procesu, nego da se na svetlo izvede da objekt saznanja kao takav uvek već jeste određen prirodom svog odnosa prema saznajnom subjektu. Sasvim precizno, objekt saznanja kao objekt saznanja nije ništa drugo do taj odnos. ${ }^{2}$ Objekt shvaćen iz odnosa prema saznajnom subjektu i kao taj odnos sâm, kod Kanta je nazvan pojavom, fenomenom. Objekt ukoliko se pojavljuje uslovljen je onim kome se pojavljuje, to jest saznajnim subjektom. Uslovljen je formama čulnosti i razuma koji su kod Kanta shvaćeni kao jedina „dva stabla ljudskoga saznanja“.3 Spoznati da forme spoznaje predmeta prethode svakom iskustvenom dodiru s njim i da zapravo jesu ono što čini mogućim predmet spoznaje kao predmet spoznaje, odnosno da one jesu a priori, zadatak je transcendentalne spoznaje. Utoliko je transcendentalna filozofija u prvom redu delatnost samoosvešćenja. Kada se imaju u vidu te opšte smernice, može se započeti i nešto neposredniji dijalog s filozofskom tradicijom kojim bi se osvetlile konkretnije manifestacije promene koja je u životu filozofije nastupila s Kantom. No, naše istraživanje u ovom radu neće se primarno voditi pitanjem o tome šta se s Kantom promenilo u filozofiji, nego šta za Kanta uopšte znači promena. Kako se u transcendentalnoj konfiguraciji subjektivnosti i odnosu čulnosti i razuma koji ona pretpostavlja pozicionira pojam promene? Kako je moguće misliti predmet s obzirom na

\footnotetext{
${ }^{2}$ Up. Perović, M. A., „Epohalni smisao Kantove filozofije”, u: Arhe 1/2004., str. 89.

${ }^{3}$ Kant, I., Kritika čistoga uma, Dereta, Beograd 2003., prev. N. Popović, str. 66.
} 
njegovu promenu? Da li je to iz Kantove vizure uopšte moguće? Mišljenja smo da se traganjem za odgovorom na ova pitanja mogu pružiti verna svedočanstva o pojedinim bitnim aspektima promene koja je s Kritikom čistog uma započela u filozofiji, ali i o izvesnim napetostima koje su bile imanentne Kantovoj kritičkoj filozofiji u celini.

Ako kod Kanta tražimo samo izolovano pojmovno određenje promene [Veränderung], može se roditi sumnja u pogledu mogućnosti ovog pojma da na svojim plećima iznese teret jednog takvog zadatka. Kant je nedvosmislen povodom njene definicije: promena jeste „spajanje kontradiktorno-suprotnih predikata u jednom i istom objektu“ [,einer Verbindung kontradiktorisch entgegengesetzter Prädikate“ $]^{4}$, tj. „spajanje kontradiktorno suprotnih odredaba $u$ egzistenciji jedne $i$ iste stvari“ [,Verbindung kontradiktorisch einander entgegengesetzter Bestimmungen im Dasein eines und desselben Dinges" $]^{5}$. Nije, prema tome, naročito teško položiti račun o samom pojmu promene kod Kanta. Znatno je, međutim, teže odgovoriti na pitanje da li je pojmovno, razumsko mišljenje kao takvo, apstrahovano od uslova čulnosti, uopšte merodavno pri polaganju takvog računa! Jedno od maločas citiranih, za istraživanje Kantovog shvatanja promene paradigmatičnih mesta, praćeno je komentarom koji sugeriše da je odgovor kenigzberškog mislioca zapravo odričan. Čisti razum [reiner Verstand], odnosno sve ono što se u širem smislu može nazvati umnošću, uopšte ne može da shvati mogućnost promene: „Kako je sad moguće da iz jednog datog stanja sleduje njemu suprotno stanje iste stvari, to ne samo što nikakav um [Vernunft] ne može da shvati bez primera, već bez opažaja on to ne može čak ni da razume. " ${ }^{\text {"6 }}$ Neophodno je, stoga, pitati zašto bi Kant smatrao da razum ne shvata kako je moguće nešto takvo kao što je promena. Da li smo s pitanjem o tome kako nešto može podrivati svoj identitet ostajući to što jeste stigli do granice mišljenja kao bitno pojmovnog? Ili smo pak s tim pitanjem ujedno uputili poziv da se bitnost mišljenja shvati drugačije?

\footnotetext{
${ }^{4}$ Kant, I., Kritika čistoga uma, str. 76; prema originalu: Kant, I., Kritik der reinen Vernunft, Suhrkamp Taschenbuch Verlag, Frankfurt am Mein 1974, str. 80 (B 49).

${ }^{5}$ Isto, str. 173; prema originalu: Kant, I., Kritik der reinen Vernunft, str. 265 (B 291, 292).

${ }^{6}$ Isto.
} 
Da li smo, kako bi to Kant hteo, pozvali da se shvati da je za istinski iskorak u znanju neophodan korak preko granica pojmovnog mišljenja kao takvog?

Da bi se na ova pitanja odgovorilo, neophodno je inicirati širi dijalog $\mathrm{s}$ tradicijom metafizike. Taj je dijalog, u stvari, pretpostavljen već samom gornjom Kantovom primedbom, jer se metafizičko mišljenje već na svojim elejskim izvorima suočava baš s nelagodom pitanja kako misliti promenu. Otud ćemo u našem radu najpre naznačiti korene filozofske problematizacije pojma promene u helenskoj misli. Razmatranje načina na koji će Kant pristupiti ovom problemu ujedno će predstavljati polazište za preispitivanje implikacija koje poimanje promene ima po celinu kritičkog projekta kenigzberškog filozofa. Kako će se pokazati, iako se kritička pažnja na njega ne usmerava sa istim intenzitetom kao što je to slučaj povodom pojmova vremena, prostora, kategorija i ideja, promena jeste jedan od pojmova u osvrtu na koje se belodanim pokazuje o kakvoj je sintezi kod Kanta reč kada se govori o apriornom znanju.

\section{ZA POVEST POJMA PROMENE: ELEJSKI IZAZOV}

Kada filozofija sebe shvati kao večno znanje o onome večnom, kao što je to od antičkih, preko Spinozinih [Baruch de Spinoza], pa, primerice, do dâna Šelingovog [Friedrich Wilhelm Joseph Schelling] rada na izgradnji jedne filozofije apsolutnog identiteta, tako često činila, za očekivati je da pojam promene bude prisiljen da svoj život nastavi u svojevrsnom egzilu na rubnim područjima onoga što je za filozofiju od istinskog interesa. Taj egzil pojma promene - ali i progon sâme promene iz onoga što bi se imalo misliti kao istinska zbiljnost - započeo je s elejskom školom starohelenske misli. ${ }^{7}$

7 U instruktivnoj odrednici „Wandel; Veränderung“ kojom za Historisches Wörterbuch der Philosophie Joakima Ritera rekonstruišu filozofsku povest pojma promene, Johanes Cahuber [Johannes Zahhuber] i Mihael Vajhenhan [Michael Weichenhan] naglašavaju da je elejsko radikalno poricanje jedno od tri glavna strujanja kada je reč o ranom helenskom filozofskom promišljanju promene. Imanentno povezana s raspravljanjima o kretanju, nastajanju i nestajanju, promena je shvatana i kao ono što se u vidljivom svetu svodi na jedan dinamički princip (Heraklit, Anaksimen), te kao ono što se zasniva na odnosima istinski bivstvujućih, elementarnih struktura (Empedokle, atomisti). Videti: Ritter, J./Gründer, K./Gabriel, 
Parmenidu se tako na putu istine otkriva da jedino što zaista jeste jeste jeste sâmo, biće. Jedino jeste istinski jeste. Nije dovoljno dosledno reći da ono u svemu jeste isto, jer za elejskog mislioca ono jeste sve, jedno, nepodeljeno, potpuno, savršeno. Ne može biće postati ni iz čega drugog, jer ništa osim bića nije. Ne može ono postati ni iz ne-bića, iz ničeg, jer ne-biće nije ništa. Kako bi za elejsko mišljenje bića i bilo mesta za ma kakvu promenu, odnosno kretanje [kinēsis]?! Kako će Aristotel potom poentirati, svaka je promena [metabolē] iz nečega u nešto. ${ }^{8}$ Parmenid pak ne dopušta da se o biću misli kao o nečem, jer za ono što se zna da jeste nešto što jeste, istovremeno se prihvata da nije ono što nije. U tome je, za Elejca, usud ljudskih mnenja: dok su ubeđena da hitaju ka znanju o onome konkretno postojećem, ona brkaju ono što jeste i ono što nije. Ono što je istinski dostojno da bude mišljeno, do reči dolazi zapanjujuće svedenim izrazom: biće jedino jeste, nema šta nije, jer što nije biće, nije ništa. Ne može ono postati ništa, jer uopšte nije mislivo predikatom mogućnosti, nego jeste totalna zbiljnost. Misteriozna boginja koja Parmenidu pokazuje put istine otud može da napomene da biće „mora ili sasvim biti ili ga nema”, te da je

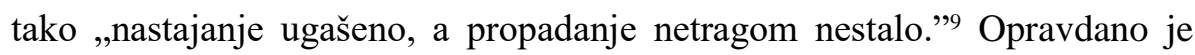
stoga naglasiti da se za Parmenida savršenstvo bića pokazuje u njegovoj statičnosti, ali i da dinamičnost nije samo znak nedostatnosti nečeg što bi bivstvovalo na nesavršen način. Dosledno elejskom stavu, dinamičnost uopšte nije. ${ }^{10} \mathrm{U}$ nastojanjima da se ta Parmenidova teza dokaže, i to onim Zenona iz Eleje, rođena je logika - ako ne kao filozofska nauka u užem smislu, onda kao praksa u strogosti filozofskog mišljenja. ${ }^{11}$

G. (Hg.)., Historisches Wörterbuch der Philosophie XII, Schvabe Verlag, Basel 1971-2007, str. 311 i dalje.

${ }^{8}$ Prema: Aristotel, Fizika, Paideia, Beograd 2006., prev. S. Blagojević, str. 197, 225a 1-5.

${ }^{9}$ Parmenid iz Eleje, „O prirodi“, u: Žunjić, S. (prir.), Fragmenti elejaca: ParmenidZenon - Melis, BIGZ, Beograd 1984., str. 69, frag. VIII, stihovi 11 i 21. Samom Parmenidovom poemom detaljnije smo se bavili u Vlaški, S., „Parmenidovo prešućeno bogoslužje“, u: Filozofska istraživanja 141 (1/2016), str. 51-63.

${ }^{10}$ Prema: Bošnjak, B., Logos i dijalektika, Naprijed, Zagreb 1961., str. 198.

11 Up. Lejewski, Cz., „Antička logika“, u Prior, A. N. (ur.), Historija logike, Naprijed, Zagreb 1970., prev. B. Petrović, str. 9-10. 
Parmenidovo učenje prema kojem jedino biće jeste i jedino se ono može misliti, Zenon je dokazivao svodeći na apsurd stavove onih koji bi tvrdili suprotno: da postoji mnoštvo, kretanje, promena. Čineći to, Zenon je na svetlo izveo aporetsku strukturu kretanja i promene. Premda u istraživanju teme kakva je naša samim Zenonovim dokazima ne može biti posvećeno više pažnje, podsećanje na pojedine njihove motive od značaja je kako bi se jasnije sagledao izazov s kojim se suočio Kant pokušavajući da integriše pojam promene u sistem transcendentalnog znanja. U tzv. aporiji strele, kako to Aristotel sažima ${ }^{12}$, elejski mislilac tvrdi da je leteća strela nepomična, jer u svakom momentu svog kretanja zauzima određeno mesto. Zauzimanje određenog mesta $u$ određenom momentu jeste pak mirovanje. Pri pokušaju da se misli suština kretanja kao promene mesta, Zenon pokazuje da se ona otkriva kao - mirovanje?! Još je prepoznatljiviji dokaz dihotomije kojim Zenon poziva da se kretanje kao promena mesta misli s obzirom na prelaženje određenog, konačnog puta od jedne do druge tačke. Prema Zenonu, takvo kretanje mislivo je samo pod pretpostavkom da se pre celine puta mora preći njegova polovina. No, pre polovine puta, mora se preći njegova četvrtina, osmina, šesnaestina itd. Rečju, konačni put koji je pred nama, mišljenju se pokazuje beskonačnim i ne dâ se misliti kako bi se kretanje uopšte moglo događati. Dakako, već među Starim Grcima javljala se volja da se Zenonovi dokazi odbace tako što bi se npr. koračanjem u određenoj prostoriji opazilo da kretanje kao promena mesta ipak jeste moguće. ${ }^{13}$ Premda je početni utisak drugačiji, ovako zasnovano odbacivanje nije i trivijalizacija Zenonovih dokaza. Zahvaljujući njemu lakše je uočiti da Zenonova meta nije čulno biće kretanja. Kako je to Hegel [Georg Wilhelm Friedrich Hegel] naglasio, Zenon ni ne poriče da se kretanje može čulima opaziti, nego da se - s obzirom na svoju protivrečnu prirodu - ne da pojmiti,

12 Videti: Zenon iz Eleje, „Dokazi“, u: Žunjić, S. (prir.), Fragmenti elejaca: Parmenid-Zenon-Melis, str. 76-77.

${ }^{13}$ Reč je o jednoj od anegdota iz života Diogena iz Sinope koju je zabeležio Diogen Laertije, a na koju se osvrće i Hegel u svojim Predavanjima o istoriji filozofije: ,,... kad je neko tvrdio da ne postoji kretanje, Diogen ustade i pođe gore-dole" (videti: Diogen Laertije, Životi i mišljenja istaknutih filozofa, Dereta, Beograd 2003., prev. A. Vilhar, knjiga VI, glava 2, frag. 39, str. 194). 
da mu ne pripada istinsko biće. ${ }^{14}$ Misliti se može samo da jeste, biće, i ono se otkriva samo mišljenju, a ne opažanju.

U Prolegomenama za svaku buduću metafiziku Kant se od čitavog dotadašnjeg idealističkog nasleđa filozofije distancira osvrćući se upravo na njegove elejske korene. Pri tome ujedno pruža osnovne smernice za razumevanje svoje vlastite koncepcije idealizma. Te reči zaslužuju da budu navedene u celosti:

„Teza svih pravih idealista od elejske škole do biskupa Berklija, sadrži se u sledećoj formuli: 'Svako saznanje stečeno čulima i iskustvom jeste samo privid, i istina se nalazi jedino u idejama čistog razuma i uma.'

Nasuprot tome, osnovni stav koji potpuno određuje i prožima moj idealizam glasi: 'Svako saznanje stvari koje potiče samo iz čistog razuma ili čistog uma jeste samo privid, i istina se nalazi samo u iskustvu'."15

Ako je dotadašnji idealizam počivao na denuncijaciji promene kao onoga što samo prividno jeste, i to za iskustvo, za očekivati je da će rehabilitacija iskustvenog znanja koju preduzima Kant značiti ponovno priznanje da i znanje o promeni jeste istinsko znanje. No, proklamacija istinitosti takvog znanja nije ono pri čemu bi Kant mogao ostati. Samokritička delatnost uma svoj pun zamah na ovom polju dobija tek onda kada krene tragom pitanja: Kako je moguće saznati promenu kao promenu? Na osnovu čega je znanje o promeni istinsko, objektivno znanje?

\section{PROMENA JE MOGUĆA USLED APRIORNOSTI VREMENA}

Odjeci elejskog negiranja promene mogu se čuti i kada se propituje smisao jedne od temeljnih razlika na kojima se gradi čitava zgrada Kantove kritičke filozofije. Reč je o razlici između analitičkih i sintetičkih sudova. Prema Kantovom poznatom određenju, analitički sudovi jesu oni sudovi u kojima se veza pojma predikata s pojmom subjekta misli na osnovu njihovog

\footnotetext{
14 Prema: Hegel, G. V. F., Istorija filozofije I, BIGZ, Beograd 1975., prev. N. M. Popović, str. 229-230.

${ }^{15}$ Kant, I., Prolegomena za svaku buduću metafiziku, Plato, Beograd 2005., prev. B. Zec, str. 123-124.
} 
identiteta. ${ }^{16} \mathrm{U}$ analitičkim sudovima, time što neko svojstvo biva predicirano subjektu, o subjektu se ne tvrdi ništa što već nije obuhvaćeno samim njegovim pojmom, nego se taj pojam raščlanjuje na njegove bitne oznake. Znanje o njemu uvećava se $u$ formalnom, ali ne i u materijalnom smislu ${ }^{17}, \mathrm{tj}$. o subjektu se ne saznaje ništa zaista novo. Šta je kriterijum da jedno takvo makar i samo formalno - proširenje znanja zaista jeste izvesno? Prema Kantu, jedan analitički sud izvestan je ukoliko predicirano svojstvo ne protivreči samom pojmu subjekta, onome što se ima misliti kao njegova suština. Utoliko, logički princip protivrečnosti otkriva se kao najviši princip svih analitičkih sudova. U Kritici čistog uma taj princip formulisan je rečima da „nijednoj stvari ne pripada predikat koji joj je protivrečan“. ${ }^{18} \mathrm{U}$ jednom od svojih predavanja iz logike kenigzberški filozof pruža dodatno pojašnjenje odnosa dva među osnovnim zakonima tradicionalne logike: „Ono čime su istinska saznanja razlikovana od lažnih, obeležje je istine. Princip identiteta formalno je obeležje istine u afirmativnim sudovima, a principium contradictionis u onim negativnim. "19 Shodno principu identiteta, odnosno neprotivrečnosti, pre svakog iskustva može se znati da svaka stvar jeste to što jeste i da nije ono što nije. Ali kako stvar može postati ono što nije ostajući ta ista stvar, tj. kako se može promeniti? Na to pitanje ne može se odgovoriti analizom samog njenog pojma. Po svom pojmu, ona jeste to što jeste i nije ono što nije. Pojmom promene stvari kao njenog postajanja onim što nije podrivali bi se temelji tradicionalne logike, kao onoga što za Kanta primarno jeste logika analize. Elejskim učenjem pak obelodanjeni su ontološki osnovi potonjih formalizacija logičkih principa. Premda se za Elejce u apsolutnoj ravni, na putu istine o kojem svedoči Parmenidova poema, zapravo ne govori o tome da svaka stvar jeste to što jeste i da nije ono što nije, nego se otkriva samo to da jedino biće (sâmo jeste) jeste, a da što biće nije - nije ništa, apsolutizacija analitičkih znanja jeste na elejskom tragu povodom onoga presudnog: samim pojmom bića

\footnotetext{
${ }^{16}$ Videti pre svega IV odeljak Uvoda u Kritiku čistoga uma (str. 57-59 citiranog izdanja).

${ }^{17}$ Prema: Kant, I., „The Jäsche logic“, in: Lectures on logic, Cambridge University Press, Cambridge 1992, transl. and ed. by J. M. Young, §36, str. 607.

${ }^{18}$ Kant, I., Kritika čistoga uma, str. 132-133.

${ }^{19}$ Kant, I., „The Blomberg logic“, in: Lectures on logic, §94, str. 67.
} 
obuhvaćeno je sve što ono jeste. Da išta može biti drugačije, da je moguća promena, pa i da mogućnost (dynamis) jeste zbiljska, o tome se može mniti, ali o tome nema istinskog znanja.

Aristotel se, primerice, s elejskim negiranjem bića promene suočio iznoseći na videlo višeznačnost bića sâmog. Toj višeznačnosti odgovara višeznačnost kretanja i promene, jer one sa svoje strane, kako naglašava Stagiranin, „ne postoje nezavisno od stvari““. ${ }^{20}$ Kretanje i promena tu se pokazuju kao bitnost prirodnih bića, jer priroda jeste „načelo kretanja i promene“ ${ }^{\text {21 }}$. Po svom biću, kretanje za Aristotela jeste zbiljnost onoga mogućeg kao mogućeg. Potpuno ozbiljenje jeste svrha onoga što je moguće, ali sa ozbiljenjem svoje svrhe ono kao moguće biva ukinuto. Paradoksalno, ono jeste zbiljsko samo dok nije u potpunosti zbiljsko, tj. zbiljsko je u svom postajanju zbiljskim - u kretanju. Tom paradoksalnošću misli se sâmo biće kretanja kao nesvršene zbiljnosti ${ }^{22}$, umesto da se ona, paradoksalnost, zenonovski shvati kao beleg njegove ništavnosti. ${ }^{23} \mathrm{U}$ centru Kantovih

\footnotetext{
${ }^{20}$ Kako Aristotel naglašava u Fizici, „[p]ostoji toliko vrsta kretanja i promene koliko je vrsta bića“ (str. 92 citiranog izdanja, 201a 9). Malo dalje, Stagiranin pojašnjava kako shvatiti tu podudarnost: „Kretanje ne postoji nezavisno od stvari, jer što se menja uvek se menja ili po bivstvu, ili po količini, ili po kakvoći, ili u odnosu na prostor“. Na drugom mestu unutar istog spisa, promena po bivstvu, tj. postajanje i propadanje, izuzima se iz onog o čemu bi se dosledno moglo govoriti kao o kretanju: „Ako se načini pridavanja (katēgoriai) određuju s obzirom na bivstvo, kakvoću, togde, to prema-nečemu, količinu, delanje i trpljenje, tada je nužno da ima tri kretanja: kretanje unutar količine, unutar kakvoće, i prostorno kretanje“ (str. 199, 225b 6-10). Od značaja za naše istraživanje jeste to što Aristotel naznačuje da se promene u smislu postajanja i propadanja ne mogu u strogom smislu misliti kao kretanje, jer u njima još uvek nema ili više nema bića kao podmeta koji bi omogućio identifikaciju kretanja (str. 198-199, 225a 25-35). U ranije pisanim Kategorijama, i to u odeljku o tzv. postpredikamentima, Aristotel o njima ipak govori kao o dvema od ukupno šest vrsta kretanja - uz postajanje i propadanje, o kretanju se i tu govori i u smislu rasta, smanjivanja, podrugojačavanja i promene mesta (prema: Aristotel, Kategorije, u: Analitika I-II. Kategorije. O izrazu, Paideia, Beograd 2008., prev. S. Blagojević, str. 51, 15a 13-15; videti i napomenu br. 39 prevodioca S. Blagojevića povodom navedenog mesta).

${ }^{21}$ Aristotel, Fizika, str. 91, 200b 12.

${ }^{22}$ Up. Isto, str. 95, $201 \mathrm{~b} 33$.

${ }^{23}$ Kako beleži Slobodan Blagojević, kod Aristotela se kretanje misli upravo kao „bivstvujuća protivrečnost, jedinstvo suprotnosti: delotvornost kao takva ukida
} 
kritičkih preispitivanja nije, međutim, pitanje o kretanju i promeni kao suštini prirodnog bića, nego o tome kako mi možemo da saznajemo nešto takvo kao što je kretanje i promena i da tom saznanju pridajemo objektivni smisao. Na kantovskom horizontu, objektivno važenje imaju jedino znanja koja važe na opšti i nužni način. ${ }^{24}$ Takva znanja ne potiču iz iskustva. Ako se prisetimo Kantove opaske da se bez opažaja - koji su, prema Kantu, za čoveka jedino mogući kao čulni - uopšte ne može shvatiti mogućnost promene, na kakvim temeljima onda počiva npr. dinamika kao nauka o čijem je uzletu svedočila čitava moderna epoha? Šta joj daje za pravo da svojim znanjima pridaje objektivno važenje?

Da se polje onoga što je u znanju nezavisno od iskustva iscrpljuje sferom dometa analitičkog suđenja, nauka poput dinamike takvo pravo ne bi ni imala. Analizom pojmova stvari neminovno se vraćamo stavu da se pouzdano zna da nešto jeste to što jeste, te da nije ono što nije. Kant je morao pretpostaviti da su znanja nauka u kojima se opredmećuje postajanje stvari onim što nisu sasvim drugačijeg tipa. U njima se istupa izvan sfere onoga što je obuhvaćeno samim pojmom stvari. Ta znanja jesu sintetička. Pitanje mogućnosti saznanja promene otud jeste pitanje sjedinjenja pojma neke stvari s nečim što mu kao pojmu nije inherentno. Sâmim pojmom promene kakvim ga razvija Kant, promena je shvaćena kao sinteza, odnosno spajanje $^{25}$, i to protivrečnih predikata u jednom i istom objektu. U svetlu naših dosadašnjih osvrtanja na elejsko učenje o biću, sasvim je indikativan primer kojim Kant pojašnjava šta jeste promena. Podsećajući kada se o predikatima govori kao o protivrečnim, Kant napominje da je o promeni reč npr. kada se sjedinjuju „,bitak i nebitak iste stvari na jednom i istom mestu“ [,das Sein an einem Orte und das Nichtsein eben desselben Dinge am

nesavršenost i obratno. To ukidanje i jedinstvo jeste kretanje“ (napomena br. 8 na str. 94 citiranog izdanja Fizike). O tome videti i predgovor zagrebačkom izdanju Aristotelove Fizike „Bitak i kretanje. Fizika i metafizika u mišljenju Aristotela“ Danila Pejovića (u: Aristotel, Fizika, Globus-Liber, Zagreb 1988., prev. T. Ladan, str. V-XXXI).

24 Up. Hegel, G. V. F., Nauka logike, Prosveta, Beograd 1973., prev. D. Nedeljković, §41, Dodatak 2, str. 122.

${ }^{25}$ Za Kanta, veza [Verbindung, conjunctio] i izrekom jeste ,predstava sintetičkog jedinstva raznovrsnosti““ (Kritika čistoga uma, str. 109). 
demselben Orte"]. ${ }^{26} \mathrm{~S}$ obzirom na promenu, može se misliti da nešto i jeste i nije, a jeste promene kao takve i za Kanta jeste sjedinjavanje bitka i nebitka sâmo. Kako je ono moguće? Kantov primer sugeriše da se suština promene ne otkriva s obzirom na prostorni karakter stvari: promena se može iskušavati iako stvar ne menja mesto, tj. ne kreće se. Iskustvo promene moguće je jedino pod pretpostavkom da se protivrečni predikati opažaju kao ono što se jedno za drugim, odnosno sukcesivno pririče stvari. Ono je moguće samo pod pretpostavkom temporalnosti! Kant je tu izričit: „Samo se $\mathrm{u}$ vremenu mogu naći obe kontradiktorno suprotne odredbe u jednoj stvari, naime jedna za drugom“. ${ }^{27}$

Na prvi pogled, može se steći utisak da se Kant time nije udaljio od principa protivrečnosti kao principa povodom kog tvrdi da jeste nužan, ali ne i dovoljan da bismo istinski proširivali znanje. Principom protivrečnosti, naime, po jednom od njegovih poznatih, aristotelovskih određenja, ističe se da je „nemoguće da nešto u isto vreme i jeste i nije“. ${ }^{28} \mathrm{~S}$ Kantovog gledišta, međutim, ako bi ta formulacija bila adekvatna, princip protivrečnosti uopšte ne bi mogao sloviti najvišim principom analitičkih znanja kao znanja izvedenih iz samih pojmova stvari. Pokazivao bi se u svojoj uslovljenosti onim što nije diskurzivnog, poopštavajućeg, već opažajnog karaktera vremenom!

$\mathrm{Na}$ problem uslovljenosti ovako formulisanog principa protivrečnosti temporalnošću, Kant je skrenuo pažnju već u svojoj inauguralnoj disertaciji iz 1770. O formi i principima čulnog $i$ inteligibilnog sveta (De mundi sensibilis atque intelligibilis forma et principiis). Kada je reč o stavu kenigzberškog filozofa prema aristotelovskom shvatanju odnosa promene i temporalnosti, $\mathrm{u}$ istom spisu zabeležena je ključna primedba: nije vreme ono što se shvata posredstvom promene kako je to tvrdio Aristotel $^{29}$,

${ }^{26}$ Kant, I., Kritika čistoga uma, str. 76; terminološki prilagođeno prema originalu: Kant, I., Kritik der reinen Vernunft, str. 80 (B 49).

27 Isto.

${ }^{28}$ Isto, str. 133.

${ }^{29} \mathrm{O}$ aristotelovskom shvatanju vremena kao prebrojavanja promena stvari, ali i o njutnovskom oponiranju ovakvoj koncepciji koje se zasniva na tezi o vremenu koje postoji i nezavisno od stvari pogledati Roveli, K., Poredak vremena, Laguna, Beograd 2019., prev. G. Skrobonja, poglavlje „Gubitak nezavisnosti”, str. 57-75. 
nego se promena može shvatiti jedino zahvaljujući vremenu! ${ }^{30}$ Prema Kritici čistoga uma, upravo je vreme kao apriorna forma čulnosti - tj. kao ono kako opažamo stvari, a ne nešto stvarsko, opaženo, niti nešto što nastaje poopštavanjem čulnih opažaja stvari - uslov mogućnosti sintetičkih apriornih znanja poput onih koja izlaže dinamika kao opšta nauka o kretanju, a za koju Kant naglašava da „nije malo plodna“31. Da ne opažamo pod vidom vremena, i sâm pojam promene kao spajanja protivrečnih odredaba ostajao bi prazan. ${ }^{32}$ Vreme za Kanta „čini mogućim i ono što je nemoguće shodno pukom pojmu stvari“ ${ }^{33}$ Raspravljanjem o mogućnosti dinamike kao nauke ne iscrpljuju se značenja tog stava!

Pre nego što više pažnje posvetimo transteorijskim aspektima Kantovog poimanja promene, neophodno je podrobnije razmotriti ono što je kod kenigzberškog mislioca razumevano stavom o promeni kao onom što je moguće na osnovu aprioriteta - dakle: subjektivnosti - vremena. Važno je, najpre, imati u vidu da je za Kanta svaka promena saznatljiva samo s

Ove koncepcije biće od neposrednog ili implicitnijeg značaja i za naše dalje istraživanje Kantovog poimanja promene.

${ }^{30}$ Prema: Kant, I., On the form and principles of the sensible and the intelligible world [inaugural dissertation], in: Theoretical philosophy, 1755 - 1770, Cambridge University Press, Cambridge 1992, translated and edited by D. Walford in collaboration with R. Meerbote, §14, 5, str. 394. O tome videti i Vaihinger, H., Kommentar zu Kants Kritik der reinen Vernunft II, Union deutsche Verlagsgesellschaft, Stuttgart/Berlin/Leipzig 1922, str. 383-390.

31 Kant, I., Kritika čistoga uma, str. 76. U Kantovim Metafizičkim polaznim načelima prirodne nauke o opštem učenju o kretanju govori se kao o samoj prirodnoj nauci. Shodno strukturi kategorijalnog aparata razuma, njenim početnim načelima kretanje se razmatra s obzirom na kvantitet (foronomija), kvalitet (dinamika), relaciju (mehaniku) i modalitet (fenomenologija) (prema: Kant, I., Metafizička polazna načela prirodne znanosti, u: Metafizika prirode, Akademska knjiga, Novi Sad 2016., prev. M. Soklić, str. 229).

32 Kako komentariše Heni Blome [Henny Blomme], „formalna logika ne uključuje vreme, a pojam promene tu vodi samo u protivrečnost. U stvari, pojam vremena ne može biti ostvaren u formalnoj logici, jer veza opposita generiše analitičku nemogućnost“ (Blomme, H., „Kant's Conception of Chemistry in the Danziger Physik", in: Clewis, R. R. (ed.), Reading Kant's Lectures, De Gruyter, Berlin 2015, str. 498; dostupno na: https://lirias.kuleuven.be/retrieve/530993).

${ }^{33}$ Kant, I., „Notes on metaphysics”, in: Notes and Fragments, Cambridge University Press, Cambridge 2005, ed. by P. Guyer, transl. by C. Bowman, P. Guyer, F. Rauscher, §5805 (1783-1784), str. 299. 
obzirom na to što bi se - baš kao i vreme i prostor - shvatila kao kontinuirana. Kantova primedba da ,između realiteta i negacije postoji jedna neprekidna veza mogućih realiteta i mogućih manjih opažaja [Wahrnehmungen] “34 usmerena je na to da istakne da se čulima ne može potvrditi prestajanje u apsolutnom smislu, odnosno potpuno odsustvo realiteta, čista negacija. Sledstveno tome, nemoguće je opaziti apsolutno počinjanje ex nihilo. U svetlu polemike s njutnovskim shvatanjem vremena, tim uvidom Kant potkrepljuje tezu o nedokazivosti učenja o praznom, apsolutnom vremenu, vremenu u kom se ne dešava ništa. Na horizontu zahteva samog kritičkog projekta, mogućnost saznanja apsolutnog počinjanja i prestajanja pokazuje se kao ono što bi onemogućavalo izgradnju jedinstvenog sistema znanja. Za Kanta, jedinstvo iskustva - ali dodajmo: i priroda sama kao ukupnost svih predmeta iskustva ${ }^{35}$ - bili bi nemogući ,ako bismo dopustili da postaju nove stvari“'36. Nužno je sada pitati: o kakvoj to rehabilitaciji promene možemo govoriti s Kantom ako ne dopuštamo da bi moglo nastati bilo šta zaista novo?!

Ovakva pitanost primorava Kanta da dodatno precizira, odnosno da ispravi sopstveni pojam promene. Nastajanje i nestajanje $\mathrm{u}$ apsolutnom smislu zapravo se ni ne mogu nazvati promenama jedne stvari. O promeni se može govoriti samo s obzirom na ono što traje. Bez pretpostavke o onome što je pri promenama postojano nikakvo saznanje prirode kao prirode ne bi ni bilo moguće. Blisko aristotelovskom spekulativnom uvidu u suštinu promene, i za Kanta se, paradoksalno, menja samo ono što - ostaje. Prema njegovim vlastitim rečima, „samo se menja ono što je postojano (supstancija), a ono što je promenljivo [das Wandelbare] ne trpi nikakvu promenu [Veränderung], već samo neku smenu [Wechsel], pošto jedne odredbe prestaju, a druge počinju“. ${ }^{37}$ No, iako vreme kao čisti opažaj čini

\footnotetext{
${ }^{34}$ Kant, I., Kritika čistoga uma, str. 141; prema originalu: Kant, I., Kritik der reinen Vernunft, str. 210 (B 211, A 169).

${ }^{35}$ Kant, I., Prolegomena za svaku buduću metafiziku, str. 47.

${ }^{36}$ Kant, I., Kritika čistoga uma, str. 149.

${ }^{37}$ Isto, str. 149; prema originalu: Kant, I., Kritik der reinen Vernunft, str. 224-225 (B 239-231, A 187-188). Shodno preduzetoj pojmovnoj diferencijaciji, o Kantovom terminu „Veränderung“ - u etimološkoj blizini aristotelovskog metabole - moglo bi se govoriti kao o predrugojačavanju (postajanje drugim, drukčijim, Ver-änderung).
} 
promenu mogućom, u ravni samog opažanja nema ničega trajnog, ničega supstancijalnog $\mathrm{s}$ obzirom na šta bi predstava promene bila moguća. Sjedinjenje opreka moguće je u vremenu, ali nije vreme sâmo ono što ih sjedinjuje. ${ }^{38}$ Jedinstvo $\mathrm{u}$ vremenu moguće je jedino zahvaljujući sjedinjujućoj delatnosti jastva, koje se, prema Kantu, u svom bitku ni ne otkriva drugačije nego kao s-jedinjujuće. Bliže određeno kao razum, ono čini mogućim sjedinjenje opažaja koje se aktualizuje kao predstava promene, i to posredstvom supstancije kao sopstvenog čistog pojma. Mogućnost promene kao sjedinjavanja protivrečnih odredaba time se otkriva u sadejstvu razuma i čulnosti, kao živa sinteza pojma i opažaja!

Čini se da je upravo to što se aktualizacija promene događa u dodiru i kao dodir razuma i čulnosti odgovorno i za izvesne dileme povodom pozicioniranja njenog pojma u Kritici čistoga uma. Dok, na primer, u tzv. pretkritičkom periodu o promeni govori kao o jednom od čistih pojmova razuma $^{39}$, već u prvom odeljku „Uvoda“ u Kritiku čistoga uma (str. 54 citiranog našeg izdanja) Kant ističe da je promena ,jedan pojam koji se može izvesti samo iz iskustva“. Utoliko sud „Svaka promena ima svoj uzrok“ jeste primer jednog apriornog suda, ali kako uključuje jedan iskustveni pojam poput pojma promene, taj sud nije i čist. Već u narednom odeljku, međutim, kenigzberški filozof na isti sud upućuje kao na primer jednog čisto apriornog suda. ${ }^{40} \mathrm{U}$ „Transcendentalnoj analitici“ (\$10, str.

\footnotetext{
${ }^{38} \mathrm{U}$ drugom izdanju Kritike čistoga uma (1787.) Kant je u pogledu toga izričit: veza raznovrsnosti ,uopšte ne može nikada da dođe u nas preko čula, te, dakle, ne može da se nalazi ni u čistoj formi čulnog opažanja“ (str. 109 citiranog izdanja).

${ }^{39}$ Videti: Kasirer, E., Kant. Život i učenje, Hinaki, Beograd 2006., prev. A. Buha, str. 108-109.

40 Odnos pojmova čistog i apriornog privlači značajnu pažnju kod istraživača Kantove filozofije. Prema Normanu Kempu Smitu [Norman Kemp Smith], gorepomenuta konfuzija koja postoji povodom tumačenja uvodnih odeljaka Kritike čistoga uma posledica je Kantove okupiranosti isključivo onim apriornim. Smit ističe da se kod Kanta o onome apriornom može govoriti u relativnom (Smitov primer je sud „Svaka nepodržavana kuća mora pasti“) i u apsolutnom smislu. Apsolutno apriorno znanje može, s jedne strane, biti mešovito - primer je upravo sud „Svaka promena ima svoj uzrok“. S druge strane, čista apsolutno apriorna znanja jesu npr. aksiomi geometrije (prema: Smith, N. K., A Commentary to Kant's Critique of Pure Reason, Palgrave Macmillan, Hampshire-New York 2003, str. 54$55)$.
} 
100), o promeni se govori kao o jednoj od predikabilija, tj. čistih, ali izvedenih pojmova razuma. ${ }^{41}$ Pobliže, promena bi se - uz pojmove postajanja i prestajanja - podređivala kategorijama (predikamentima) modaliteta (mogućnost - nemogućnost, postojanje - nepostojanje, nužnost slučajnost). Na osnovu toga dalo bi se razmišljati i o aspektima približavanja Kantovog shvatanja promene njenom aristotelovskom pojmu, po kojem smo o promeni već govorili kao o zbiljnosti onoga mogućeg kao mogućeg. Dalje, u okvirima „Opšte primedbe o sistemu osnovnih stavova“ čistoga razuma, reč je čak i o potrebi da se promena predstavi „kao opažaj koji odgovara pojmu kauzaliteta“" (str. 173).

Važnije od pokušaja da se fiksira koncepcijsko mesto pojma promene jeste ukazati na stanovitu višeznačnost koja je u pogledu tog pojma za Kanta zapravo ključna: nema nikakvog apriornog, odnosno opštevažećeg i nužnog odgovora na pitanje kako nešto promeniti, bilo da je reč o promeni u fizičkom, psihološkom, socijalno-političkom ili bilo kom drugom smislu. Isto tako, da bismo saznali kako se odvija promena nečeg, neophodna nam je pomoć iskustva. To Kant iznova i iznova naglašava: „Kako se sad uopšte nešto može promeniti, kako je moguće da posle jednoga stanja u jednome trenutku može u drugome trenutku da dođe jedno suprotno stanje, mi o tome nemamo a priori ni najmanjeg pojma. Za to je potrebno saznanje realnih sila, saznanje koje se samo empirički može dobiti““. ${ }^{42}$ No, iako nemamo nikakvih apriornih znanja o onome što bi činilo materiju promene, mi, prema Kantu, nezavisno od iskustva možemo znati kako je uopšte moguće iskusiti nešto takvo kao što je promena. Prema tome, a priori možemo znati formu promene kao promene i zahvaljujući tom znanju, uostalom, u kantovskoj perspektivi je moguća čista prirodna nauka kao nauka o kretanju. Saglasno temeljnom uvidu čitave transcendentalne filozofije, forma, tj. uslovi pod kojima nam se pojavljuje određeni sadržaj, nije nešto puko naspramno tom sadržaju kao svom predmetu. U sferi pojavnosti predmeta, uslovi pod kojima

${ }^{41}$ U Prolegomenama Kant pojašnjava da za njega predikabilije jesu pojmovi koji su izvodljivi iz kategorija kao predikamenata, i to ,putem njihovog povezivanja ili među sobom, ili s čistom formom pojave (vreme i prostor), ili s njihovom materijom ukoliko ona još nije empirijski određena“ (Kant, I., Prolegomena za svaku buduću metafiziku, str. 74-76).

${ }^{42}$ Kant, I., Kritika čistoga uma, str. 157-158 (podvukao S. V.). 
nam se on pojavljuje ujedno su ono što ga čini mogućim kao pojavni predmet. Uslovi mogućnosti našeg iskustva promene predmeta uslovi su mogućnosti njegove promene sâme i oni upućuju na temporalnu prirodu našeg opažanja. Temporalnost opažanja kod Kanta se otkriva kao nužna određenost budućeg vremena prošlim vremenom. Da ne opažamo tako, predstava o promeni jedne stvari ne bi mogla biti artikulisana. Ako se, međutim, zna da se u opažajnoj ravni sve pojavljuje samo u svojoj pojedinačnosti, kao ono „sada“ i „ovde“, ostaje pitanje kako se onda misaono uobličuje ta predstava o onome prošlom kao o onome što nužno određuje ono buduće. Za Kanta, takva veza moguća je na osnovu temporalne prirode opažanja, ali, ponovo, predstave o toj vezi nema u opažanju samom. Ona jeste actus razuma, i to kao kategorija kauzaliteta. Na taj način treba pristupiti Kantovom zaključku da je svaka promena, na koncu, moguća „samo na osnovu kontinuiranog delanja kauzaliteta“. ${ }^{43}$

Pitati o promeni u apsolutnom smislu isto je pak što i pitati o promeni ukoliko je razrešavamo od uslova pod kojima je konstituiše naša opažajnost. To pitanje drugo je lice pitanosti o tome kako misliti promenu u kojoj bi se apsolutno presecale veze sa svim onim što je prošlo. Kako misliti ono što bi samo po sebi, a ne samo za nas bilo promena, kao nastajanje ex nihilo? Prema Kantu, mi, doduše, možemo misliti o takvoj, supstancijalnoj promeni, ali saznati možemo samo promene stanja postojane supstancije, koje se uvek pojavljuju u svojoj uslovljenosti prošlim stanjima. Ne samo u svetlu raspravljanja metafizičke teologije o božanskom stvaranju univerzuma iz ničeg, nego i kada se uzme u obzir da doba u kojem kritička filozofija dostiže svoj zenit jeste doba revolucionarnih promena života Zapada, doba

43 Isto, str. 158. Vredi ovde napomenuti da Konrad Kramer [Konrad Cramer], imajući u vidu, s jedne strane, suštinski značaj koji se pojmu promene pridaje u kontekstu Kantovog raspravljanja o zakonu kauzaliteta kao jednom od osnovnih stavova sintetičke upotrebe razuma uopšte, te, s druge strane, smisao Kantove primedbe o ne-čistom karakteru pojma promene iz prvog odeljka „Uvoda“" u Kritiku čistoga uma, zaključuje da se pitanje o mogućnosti sintetičkih apriornih znanja prirodne nauke rešava upravo u okvirima diskusije o ne-čistom sintetičkom apriornom znanju (videti: Cramer, K., „Non-pure Synthetic A Priori Judgments in the Critique of Pure Reason", in: Beck, L. W. (ed.), Proceedings of the Third International Kant Congress (Held at the University of Rochester, March 10-April 4, 1970), D. Reidel Publishing Company, Dordrecht-Holland 1972, str. 246-254). 
sveprožimajuće želje da se u svim njegovim rejonima počne $o d$ početka, reči predvodnika filozofske revolucije čuju se kao upozorenje: sve ono što mi zaista možemo znati puka je promena onoga postojećeg, a ne nastajanje iz niče ${ }^{44}$. Da li je to Kantova završna reč u raspravi o poimanju promene?

\section{PROMENA NEMA APSOLUTNA PRAVA}

Tezu o nemogućnosti saznanja apsolutne promene Kant u Kritici čistoga uma dalje obrazlaže i u okvirima razmatranja ,antinomije čistoga uma“. Za naše istraživanje simptomatično je to što se upravo u sklopu ovog razmatranja Kant izrekom osvrće na filozofske zasluge Zenona iz Eleje. ${ }^{45}$ Nasuprot Platonu, za kojeg je Zenon, kako to konstatuje Kant, samo drski sofista, Kant o elejskom misliocu govori kao o suptilnom dijalektičaru čiji rad zaslužuje da bude iznova filozofski vrednovan. Zenon je obelodanio ono što će Kant nazvati dijalektičkom suprotnošću u delatnosti uma. Osvrt na ono što je za Kanta značila dijalektička suprotnost od značaja je za određenje statusa pojma promene u registrima kritičkog određivanja granica teorijskog znanja. Elejac je Kantu pokazao kako oprečni stavovi poput onih „Univerzum je u stalnom kretanju“ i „Univerzum miruje“ - za razliku od kontradiktornih suprotnosti - mogu istovremeno biti lažni, jer u njima kriterijum na osnovu kog se gradi odnos suprotstavljanja nema apsolutni legitimitet. O kretanju i mirovanju i tu se razmišlja kao o promeni ili nemenjanju mesta kao prostorne odrednice. Zenon je, prema Kantu, pokazao da se o „mestu“ smisleno može govoriti samo unutar onoga što se naziva univerzumom, te da se „menjanje mesta“ ili "ostajanje na istom mestu“ univerzumu uopšte ne mogu pripisivati kao predikati koji bi mimo njega, tj. sami po sebi, imali bilo kakvo važenje. Ako se vratimo kantovskim razmatranjima načina na koji promena kao takva jeste, implikacije će se

\footnotetext{
${ }^{44}$, ,...] Ovo postajanje ne odnosi se [...] na supstanciju (jer ona ne postaje), već na njeno stanje. Ono je, dakle, samo promena, a ne postajanje iz ničega“ [,Es ist also bloß Veränderung, und nicht Ursprung aus Nichts"] - Kant, I., Kritika čistoga uma, str. 157; prema originalu: Kant, I., Kritik der reinen Vernunft, str. 239 (B 252, A 207).

45 Videti zaključni deo „Sedmog odseka antinomije čistoga uma“, str. 275-277 citiranog izdanja.
} 
pokazati srodnim. Ako je promena saznatljiva samo kao sukcesija odredaba u vremenu - a za nas, prema Kantu, ništa drugo nije moguće - iluzorna je suprotnost koju obrazuju odgovori na pitanje da li se stvari menjaju same po sebi, ili su same po sebi nepromenljive. Postavljanjem pitanja o vremenskoj sukcesiji odredaba, mi nužno pitamo o tome kako nam se stvari pojavljuju, kako jesu za naša čula koja su temporalno strukturirana, a ne kakve su same po sebi. One nam se pojavljuju u svojoj determinisanosti nečim prošlim, nikad kao ono što bi počinjalo samo od sebe, te se o stvarima kakve su po sebi ne može razmišljati u okvirima pojma promenljivosti. Ako, s druge strane, imamo na umu da svaka promena pretpostavlja nešto supstancijalno, šta nas onda sprečava da tvrdimo da su stvari u supstancijalnom smislu nepromenljive, večne? Nesavladivu prepreku takvim pokušajima predstavlja to što, prema Kantu, i sâm pojam supstancije kao čisti pojam razuma svoju konkretnost nalazi samo s obzirom na predstavu o trajanju vremena ${ }^{46}$ koje, opet, jeste medijum pojavnosti i forma naše čulnosti, a ne apsolutno realno svojstvo stvari. ${ }^{47}$

Ova objašnjenja dotiču se jednog od glavnih problema koji su inicirali pisanje Kritike čistoga uma. Kant je, naime, već u spominjanoj

46 Videti pre svega „Prvu analogiju iskustva“, Kritika čistoga uma, str. 147-150, ali i Kantovu primedbu iz važnog pisma Markusu Hercu od 21. februara 1772.: ,[...]Ako bi se htelo reći da odatle sledi da bi sve u svetu bilo objektivno i samo po sebi nepromenljivo, odgovorio bih: nije sve ni promenljivo, niti nepromenljivo [...] ono apsolutno nemoguće nije ni hipotetički moguće niti nemoguće, jer ono uopšte ne može biti razmatrano ni pod kakvim uslovom; tako isto: stvari sveta objektivno ili same po sebi nisu ni u jednom istom stanju u različitim vremenima, niti u različitim stanjima, jer tako razumevane one uopšte nisu predstavljene u vremenu." (Kant an Herz, den 21. Febr. 1772, u: Immanuel Kant's vermischte Schriften und Briefwechsel, hg. von J. H. V. Kirchmann, L. Heimann's Verlag, Berlin 1873, str. 408-409)

${ }^{47}$ Pitanje o bliskosti Kantove koncepcije s učenjem elejskog filozofa nije među onim koja su privlačila najviše pažnje kod istraživača. Već je Hegel, međutim, ukazao na tu bliskost: ,[...] ono što je opšte u dijalektici, opšti stav eleatske škole bio je ovaj: 'Ono što je istinito jeste samo Jedno, sve ostalo je neistina;' kao što je rezultat Kantove filozofije ovo: 'Mi saznajemo samo pojave'. Uopšte uzev to je jedan isti princip: 'Sadržina svesti je samo jedna pojava, ništa istinito'، (Hegel, G. V. F., Istorija filozofije I, str. 239). Za Hegela se Zenon pokazao doslednijim u odnosu na Kanta utoliko što je, radikalizujući misao o Jednom, o jeste koje jedino jeste, negirao posebičnost sveta uopšte, a ne samo znanja o njemu. 
disertaciji iz 1770. godine zastupao stav o subjektivnom karakteru vremena i prostora. Kada se zna kako su tu tezu protumačili njegovi tada izuzetno cenjeni filozofski savremenici poput Lamberta [Johann Heinrich Lambert] i Mendelsona [Moses Mendelssohn], pokazuje se da se već tada Kant našao u situaciji da se brani pred optužbom da je implicite prigrlio elejsko stanovište kojim se negira zbiljnost promene. Te optužbe temeljile su se na uverenju da poricanjem objektivnosti vremena svaka promena biva svedena na privid. $U$ pismu Kantu, Lambert rezonuje silogistički: „Sve promene povezane su s vremenom i bez vremena ne daju se misliti. Ako su promene stvarne, onda je $i$ vreme stvarno, šta god ono bilo. Ako vreme nije stvarno, onda nijedna promena ne može biti stvarna." Lambert je nedvosmislen u pogledu toga da raspravlja s filozofskim idealizmom: po njegovom sudu, čak i idealista morao bi prihvatiti da promene jesu stvarne i „da se javljaju u njegovim predstavama“ ${ }^{48}$ Ovom prigovoru Kant je posvetio dosta pažnje kako u danima koji su prethodili ispunjenju zadatka kritike uma ${ }^{49}$, tako i u samoj Prvoj kritici ${ }^{50}$. Kako je filozof na njega odgovorio? Za Kanta, promene - baš kao i vreme - jesu nešto stvarno, ali sam pojam stvarnog za Kanta je dvoznačan! S jedne strane, svako naše iskustvo odvija se pod vidom vremena. Kao empirijski stvarna potvrđuje se i promena - stvari se našim čulima pojavljuju u sukcesiji svojih odredaba, pri čemu sukcesivnu vezu kao takvu uspostavlja razum. Ono sadašnje, stoga, jeste determinisano onim prošlim. No, empirijska stvarnost promene ne sme se poistovetiti s apsolutnom, noumenalnom stvarnošću. Razlika pojavnosti i onoga

48 Lambert an Kant, Anfang December 1770, u: Immanuel Kant's vermischte Schriften und Briefwechsel, str. 378-379. O Lambertovom prigovoru Kantu, ali i o Mendelsonovoj kritici Kantovog poimanja vremena kao subjektivne forme predstavljanja kao kritike koja polazi od fakta da i sâm subjekt koji opaža jeste objekt predstavljanja videti Falkenstein, L., „Kant, Mendelssohn, Lambert, and the Subjectivity of Time“, in: Journal of the History of Philosophy, Vol. 29, No. 2, April 1991, str. 227-251.

${ }^{49} \mathrm{U}$ citiranom pismu Hercu Kant o Lambertovom prigovoru tezi o subjektivnosti vremena piše kao o onom koji bi mogao biti ,najbitniji koji bi se učenju mogao uputiti“" (Kant an Herz, den 21. Febr. 1772, str. 408).

${ }^{50} \mathrm{U}$ sedmom paragrafu „Transcendentalne estetike“ Kant ponavlja Lambertov prigovor smatrajući ga paradigmatičnim: ,[...]On glasi ovako: promene su stvarne (to dokazuje smenjivanje naših sopstvenih predstava, baš i kad bismo hteli odricati sve spoljašnje pojave zajedno $s$ njihovim promenama). Promene su pak moguće samo u vremenu, usled čega je vreme nešto stvarno“ (Kritika čistoga uma, str. 78). 
noumenalnog kod Kanta se ne uspostavlja kao nešto naprosto činjenično. Ta razlika opravdana je onim što se shvata kao primarna svrha uma uopšte, a nju Kant vidi u domenu onoga praktičkog, to jest u našem slobodnom delanju. Kada bi promenama pripadao apsolutni realitet, odnosno ako bi apsolutno realan bio zakon uzročno-posledične veze zahvaljujući kojem promena kao promena jeste moguća, nikakve slobode ne bi ni bilo. Nije, dakako, teško odgovoriti na pitanje kako se kod Kanta uopšte zna da slobodi pripada bilo kakva zbiljnost. Prema Kritici praktičkog uma, moralni zakon jeste razlog zbog kojeg znamo za slobodu, baš kao što sa svoje strane sloboda jeste ono zahvaljujući čemu jeste moralni zakon. ${ }^{51}$ Čineći ono što nalaže moralni zakon našeg uma, i to za dobro moralnog zakona - samo zbog toga što tako treba, a ne zato što bismo bili potaknuti bilo kojim drugim pokretačem - mi in actu potvrđujemo ono što je teorijski apsolutno nespoznatljivo. U odluci da se postupi moralno živi misao o jednom apsolutnom početku, početku apsolutno neuslovljenom svim onim što je bilo, počinjanju ex nihilo, počinjanju od sebe! Kantovo objašnjenje mogućnosti promene tezom o vremenu kao formi našeg opažanja koja prethodi svakom konkretnom čulnom opažaju, tako se pokazuje plodnim i povrh užih teorijskih okvira rasprave o mogućnosti sintetičkih apriornih znanja. Za Kanta, uslov mogućnosti svake promene jeste - u nama samima, ali način na koji je on shvatio samu prirodu promene i njenu utemeljenost u apriornim strukturama subjektivnosti sprečio ga je da promeni prida najviši antropološki dignitet. Temporalnošću našeg opažanja omogućen je govor o promeni kao promeni, ali kako je temporalnost mišljena s obzirom na odlučujuću ulogu onoga prošlog, slobodnim ostajemo samo pod pretpostavkom postojanja jedne atemporalne (,inteligibilne“) dimenzije našeg bića, pa otud i sfere u kojoj se transcendira promenljivost kao takva.

Problemske analize Milana Kangrge dotiču samu srž onoga što se kod Kanta rađalo kao istinski novum: nije li upravo moralno trebanje movens suštinski duhovne, povesne promene čija je bitnost $u$ onome što tek treba biti, tj. u onome budućem, a ne u onome prošlom? Kant je ipak pred tim novumom ustuknuo. $^{52}$ Beleška po kojoj ,nije samo biće ono što je po sebi nužno

\footnotetext{
${ }^{51}$ Prema: Kant, I., Kritika praktičkog uma, Plato, Beograd 2004., prev. D. Basta, str. 6.

52 Videti npr. Kangrga, M., Praksa, vrijeme, svijet, Nolit, Beograd 1984., str. 158.
} 
nepromenljivo, nego je takvo sve što je inteligibilno"53 može se shvatiti kao ishod njegovih decenijskih sučeljavanja s problemom koji je filozofija upoznala u Parmenidovoj i Zenonovoj misli, problemom promene. Kod Kanta, regija ideje jednog apsolutnog početka, za čiju je mogućnost on jedino istinski zainteresovan, jeste ona koja se tiče naše moći da počnemo sami od sebe kao moralna bića. Ta regija biva odbranjena jedino time što prihvatamo da u tome što stvarno započnemo nastojeći da ostvarimo svoje moralne ciljeve istovremeno gubimo apsolutnu vlast nad svojim delima i priznajemo vlast prirodnog kauzaliteta. Drugačije rečeno, mogućnost apsolutne promene kao počinjanja volje od apsolutnog početka čuvamo jedino uz svest da se stvarno ništa ne menja. Sasvim je pak drugo pitanje da li se kod Kanta takvom odbranom ideje apsolutnog početka njoj ujedno brani da bude bilo čim drugim osim jednom apstrakcijom.

\section{LITERATURA}

Aristotel, Fizika, Paideia, Beograd 2006., prev. S. Blagojević.

Aristotel, Kategorije, u: Analitika I-II. Kategorije. O izrazu, Paideia, Beograd 2008., prevod i komentari S. Blagojević, str. 3-74.

Blomme, H., „Kant's Conception of Chemistry in the Danziger Physik”, in: Clewis, R. R. (ed.), Reading Kant's Lectures, De Gruyter, Berlin 2015, str. 498; dostupno na: https://lirias.kuleuven.be/retrieve/530993 (pristupljeno: 20.2.2021.)

Bošnjak, B., Logos i dijalektika, Naprijed, Zagreb 1961.

Cramer, K., „Non-pure Synthetic A Priori Judgments in the Critique of Pure Reason", in: Beck, L. W. (ed.), Proceedings of the Third International Kant Congress (Held at the University of Rochester, March 10-April 4, 1970), D. Reidel Publishing Company, Dordrecht-Holland 1972, str. 246-254.

Falkenstein, L., „Kant, Mendelssohn, Lambert, and the Subjectivity of Time“, in: Journal of the History of Philosophy, Vol. 29, No. 2, April 1991, str. 227251.

Hegel, G. V. F., Istorija filozofije I, BIGZ, Beograd 1975., prev. N. M. Popović. Hegel, G. V. F., Nauka logike, Prosveta, Beograd 1973., prev. D. Nedeljković. Kangrga, M., Praksa, vrijeme, svijet, Nolit, Beograd 1984.

${ }^{53}$ Kant, I., „Notes on metaphysics”, §5811 (1783-1784), str. 299. 
Kant, I., Kritika čistoga uma, Dereta, Beograd 2003., prev. N. Popović.

Kant, I., Kritik der reinen Vernunft, Suhrkamp Taschenbuch Verlag, Frankfurt am Mein 1974.

Kant, I., Lectures on logic, Cambridge University Press, Cambridge 1992., transl. and ed. by J. M. Young.

Kant, I., Prolegomena za svaku buduću metafiziku, Plato, Beograd 2005., prev. B. Zec.

Kant, I., On the form and principles of the sensible and the intelligible world [inaugural dissertation], in: Theoretical philosophy, 1755-1770, Cambridge University Press, Cambridge 1992, translated and edited by D. Walford in collaboration with R. Meerbote, str. 373-416.

Kant, I., Metafizička polazna načela prirodne znanosti, u: Metafizika prirode, Akademska knjiga, Novi Sad 2016., prev. M. Soklić, str. 219-319.

Kant, I., Notes and Fragments, Cambridge University Press, Cambridge 2005, ed. by P. Guyer, transl. by C. Bowman, P. Guyer, F. Rauscher.

[Kant, I.] Immanuel Kant's vermischte Schriften und Briefwechsel, hg. von J. H. V. Kirchmann, L. Heimann's Verlag, Berlin 1873.

Kant, I., Kritika praktičkog uma, Plato, Beograd 2004., prev. D. Basta.

Kasirer, E., Kant. Život i učenje, Hinaki, Beograd 2006., prev. A. Buha.

Laertije, D., Životi i mišljenja istaknutih filozofa, Dereta, Beograd 2003., prev. A. Vilhar.

Lejewski, Cz., „Antička logika“, u: Prior, A. N. (ur.), Historija logike, Naprijed, Zagreb 1970., prev. B. Petrović, str. 9-30.

Pejović, D., „Bitak i kretanje. Fizika i metafizika u mišljenju Aristotela“, u: Aristotel, Fizika, Globus-Liber, Zagreb 1988., prev. T. Ladan, str. VXXXI.

Perović, M. A., „Epohalni smisao Kantove filozofije”, u: Arhe 1/2004., str. 7-21.

Ritter, J./Gründer, K./Gabriel, G. (Hg.), Historisches Wörterbuch der Philosophie XII, Schvabe Verlag, Basel 1971-2007.

Roveli, K., Poredak vremena, Laguna, Beograd 2019., prev. G. Skrobonja.

Smith, N. K., A Commentary to Kant's Critique of Pure Reason, Palgrave Macmillan, Hampshire-New York 2003.

Vaihinger, H., Kommentar zu Kants Kritik der reinen Vernunft I-II, Union deutsche Verlagsgesellschaft, Stuttgart/Berlin/Leipzig 1922.

Vlaški, S., „Parmenidovo prešućeno bogoslužje“, u: Filozofska istraživanja 141 (1/2016), str. 51-63.

Žunjić, S. (prir.), Fragmenti elejaca: Parmenid - Zenon - Melis, BIGZ, Beograd 1984. 


\title{
STANKO VLAŠKI \\ University of Novi Sad, Faculty of Philosophy
}

\section{KANT'S CONCEPT OF ALTERATION}

\begin{abstract}
The article demonstrates that the meaning of the revolution which has happened in philosophy with Kant's critical philosophy can be interpreted by the inquiry concerning Kant's very concept of alteration [Veränderung]. The author thematizes Kant's observation that the understanding alone cannot grasp the possibility of the alteration as related to some of the fundamental insights of the Western metaphysics, precisely with the Eleatic negation of the thoughtfulness of the alteration and the moving, viz. with the Eleatic negation of the reality of kinessis as such. The author tries to show that Kant's integration of the concept of alteration within the system of transcendental knowledge of the subjectivity one should interpret in the light of his efforts to reveal conditions of synthetic a priori knowledge. Alteration shows itself for the lively cooperation of understanding and sensibility, concept and intuition, and as this cooperation as such. In the final chapter, Kant's thesis that the alteration is possible due to a priori character of time thesis by which one also accepts that everything that belongs to the future is necessary determined by the past, and therefore necessary validity of the law of causality - is interpreted as the key for the understanding of the reasons why Kant rejects possibility of the recognition of the absolute value of alteration. For Kant, one should not absolutize such deterministic concept of alteration, for the good of moral freedom as the sphere where human finds its true dignity. Therefore, this sphere from the Kantian standpoint has to transcend every discussion concerning the alteration.
\end{abstract}

Keywords: Kant, alteration, analytic knowledge, synthetic a priori judgements, time, causality, Parmenides, Zeno of Elea, beginning, freedom

Primljeno: 1.3 .2021 .

Prihvaćeno: 9.5.2021. 
